Research paper

\title{
Effectiveness of collaborative care in reducing suicidal ideation: An individual participant data meta-analysis.
}

Christos Grigoroglou ${ }^{a, *}$, Christina van der Feltz-Cornelis ${ }^{c}$, Alexander Hodkinson ${ }^{\mathrm{b}}$, Peter A. Coventry ${ }^{\mathrm{d}}$, Salwa S. Zghebi ${ }^{\mathrm{b}}$, Evangelos Kontopantelis ${ }^{\mathrm{e}}$, Peter Bower ${ }^{\mathrm{b}}$, Karina Lovell $^{\mathrm{f}, \mathrm{g}}$, Simon Gilbody ${ }^{\mathrm{c}}$, Waquas Waheed ${ }^{\mathrm{b}}$, Christopher Dickens ${ }^{\mathrm{h}}$, Janine Archer ${ }^{\mathrm{i}}$, Amy Blakemore $^{\mathrm{f}}$, David A. Adler ${ }^{\mathrm{j}}$, Enric Aragones ${ }^{\mathrm{k}}$, Cecilia Björkelund ${ }^{\mathrm{l}}$, Martha L. Bruce ${ }^{\mathrm{m}}$, Marta Buszewicz ${ }^{\mathrm{n}}$, Robert M. Carney ${ }^{\circ}$, Martin G. Cole ${ }^{\mathrm{p}}$, Karina W. Davidson ${ }^{\mathrm{q}}$, Jochen Gensichen ${ }^{\mathrm{r}}$, Nancy K. Grote ${ }^{\mathrm{s}}$, Joan Russo ${ }^{\mathrm{t}}$, Klaas Huijbregts ${ }^{\mathrm{u}}$, Jeff C. Huffman ${ }^{\mathrm{v}}$, Marco Menchetti ${ }^{\mathrm{w}}$, Vikram Patel ${ }^{\mathrm{x}}$, David A. Richards ${ }^{\mathrm{y}, \mathrm{z}}$, Bruce Rollman ${ }^{\mathrm{aa}}$, Annet Smit ${ }^{\mathrm{ab}}$, Moniek C. Zijlstra-Vlasveld ${ }^{\text {ac }}$, Kenneth B. Wells ${ }^{\text {ad, ae }}$, Thomas Zimmermann ${ }^{\text {af }}$, Jurgen Unutzer ${ }^{t}$, Maria Panagioti ${ }^{\mathrm{b}}$

\footnotetext{
${ }^{a}$ Division of Population Health, Health Services Research \& Primary Care, University of Manchester, Manchester, England

${ }^{\mathrm{b}}$ National Institute of Health Research School for Primary Care Research, Division of Population Health, Health Services Research \& Primary Care, University of Manchester, Manchester, England

${ }^{c}$ Department of Health Sciences, Hull York Medical School, HYMS, University of York, York, England

d Department of Health Sciences, University of York, York, England

${ }^{\mathrm{e}}$ Faculty of Biology, Medicine and Health, Division of Informatics, Imaging and Data Sciences, University of Manchester, Manchester, England

${ }^{\mathrm{f}}$ Division of Nursing, Midwifery and Social Work, School of Health Sciences, University of Manchester, Manchester, England

${ }^{g}$ Greater Manchester Mental Health NHS Foundation Trust, Manchester, England

${ }^{\mathrm{h}}$ Mental Health Research Group, University of Exeter Medical School, England

${ }^{i}$ School of Health and Society, School of Health and Society, University of Salford, England

${ }^{\mathrm{j}}$ Departments of Psychiatry and Medicine, Tufts Medical Center and Tufts University School of Medicine, England

${ }^{\mathrm{k}}$ Institut Universitari d'Investigació en Atenció Primària Jordi Gol (IDIAPJGol), Barcelona, Spain

${ }^{1}$ Primary Health Care School of Public Health and Community Medicine, University of Gothenburg, Gothenburg, Sweden

${ }^{\mathrm{m}}$ Department of Psychiatry, Geisel School of Medicine at Dartmouth, Hanover, New Hampshire, USA

${ }^{\mathrm{n}}$ Institute of Epidemiology and Health, Faculty of Population and Health Sciences, University College London, London, England

${ }^{\circ}$ Department of Psychiatry, Washington University in St. Louis (WUSTL), St. Louis, Missouri, USA

${ }^{\mathrm{p}}$ Department of Psychiatry, St. Mary's Hospital Center, McGill University, Montreal, Quebec, Canada

${ }^{\mathrm{q}}$ Institute of Health Innovations and Outcomes Research, Feinstein Institutes for Medical Research, Northwell Health, Manhasset, New York, USA

${ }^{\mathrm{r}}$ Institute of General Practice and Family Medicine, LMU Klinikum, Ludwig-Maximilians, University Munich Pettenkoferstr. 10 , 80336 Munich, Germany

${ }^{s}$ School of Social Work, University of Washington, Seattle, USA

${ }^{\mathrm{t}}$ Department of Psychiatry and Behavioral Sciences, University of Washington, Seattle, USA

${ }^{\mathrm{u}}$ Department of Psychiatry and Amsterdam Public Health Research Institute, Amsterdam, Netherlands

${ }^{v}$ Harvard Medical School, Department of Psychiatry, Massachusetts General Hospital, Boston, Massachusetts

${ }^{\mathrm{w}}$ Department of Biomedical and Neuromotor Sciences, University of Bologna, Bologna, Italy

${ }^{\mathrm{x}}$ The Pershing Square Professor of Global Health, Harvard Medical School, Boston, MA, USA

${ }^{\mathrm{y}}$ Institute of Health Research, University of Exeter College of Medicine and Health, Exeter, England

${ }^{\mathrm{z}}$ Western University of Norway, Bergen, Norway

${ }^{\text {aa }}$ Center for Behavioral Health, Media and Technology, University of Pittsburgh School of Medicine, Pittsburgh, PA, USA

${ }^{\mathrm{ab}}$ HAN University of Applied Sciences, Nijmegen, Netherlands

${ }^{\text {ac }}$ ZonMw, The Netherlands Organisation for Health Research and Development, The Hague, Netherlands

ad Department of Psychiatry and Biobehavioral Sciences, University of California, Los Angeles, USA

ae Jane and Terry Semel Institute for Neuroscience and Human Behavior, University of California, Los Angeles, USA

${ }^{\text {af }}$ Department of General Practice / Primary Care, Centre for Psychosocial Medicine, University Medical Centre Hamburg-Eppendorf, Hamburg, Germany
}

\footnotetext{
* Corresponding author at: Centre for Health Economics, Division of Population Health, Health Services Research and Primary Care, School of Health Sciences,

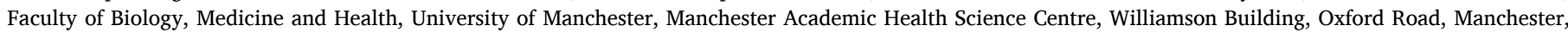
M13 9PL, UK.

E-mail address: Christos.grigoroglou@manchester.ac.uk (C. Grigoroglou).
} 


\section{O B J E C T I V E}

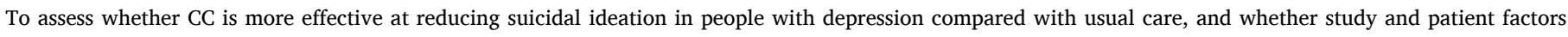
moderate treatment effects.

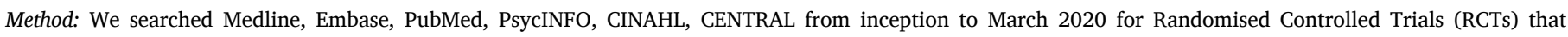

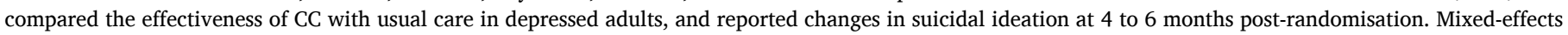
models accounted for clustering of participants within trials and heterogeneity across trials. This study is registered with PROSPERO, CRD42020201747.

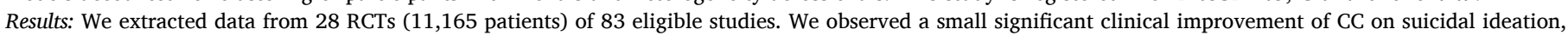

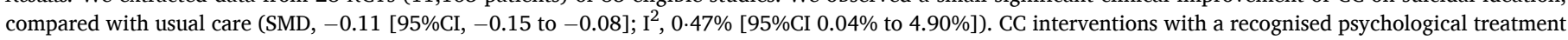

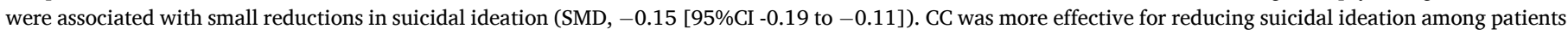
aged over 65 years (SMD, -0.18 [95\%CI -0.25 to -0.11$]$ ).

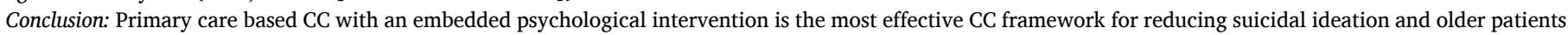
may benefit the most.

\section{Introduction}

Suicidal ideation is one of the strongest predictors of suicide, which is one of the leading causes of death worldwide. [1] Suicidal ideation is regularly measured in patient randomised trials with follow-up as opposed to suicide attempt and death by suicide, which are more clinically relevant and devastating outcomes but also extremely rare. [2] Psychosocial interventions may serve as appropriate interventions for suicidal ideation, particularly when suicidal ideation occurs concomitantly with depression. [3] Most depressed patients are treated only in primary care [4] and over two thirds of people successfully attempting suicide are in contact with their primary care physician shortly before death. Primary care offers an ideal setting for implementing suicide prevention for people with depression. [5-7]

Collaborative care (CC) has been tested in both high, middle and lowincome countries and it is now becoming increasingly used for the management of depression within primary care settings. [8,9] CC typically applies an interdisciplinary team-based care model consisting of a care manager, a primary care doctor and a consultant psychiatrist working with a patient. This follows the chronic care model, providing three aspects: 1) the patient has regular appointments with the nursecare manager who monitors how the patient is doing and all actions that have to happen for treatment. In some cases, nurse care-manager also provides some psychotherapeutic treatment to the patient, for example problem solving treatment. 2) The care manager will inform the general practitioner about the treatment progress and if needed, the general practitioner will see the patient for providing antidepressant medication or treatment of any other chronic medical condition. 3) The patient can also ask the consultant psychiatrist for advice or for a consultation in the primary care clinic, in case of suicidal ideation or questions about medication or referral to the specialist mental health care setting. In this way, it brings specialist expertise in the domain of common mental disorders, most often depressive and anxiety disorders, within reach of care providers in the generalist primary care setting, and this is of crucial importance for detection and treatment of suicidal ideation, which is in general, a task that requires specialist knowledge. [10] There is ample evidence that CC is more effective for reducing depressive symptoms at short, medium and long-term compared to usual care. [8] Furthermore, multilevel interventions that include comprehensive and integrated approaches to care, such as CC, can be particularly effective suicide prevention strategies due to their synergistic potential. [10]

Two previous trials have demonstrated that CC has the potential to lead to reductions in suicidal ideation for people with depression. [11-13] However, the vast majority of CC trials for depression have not reported baseline or follow-up data on suicidal ideation and therefore the effect of CC on suicidal ideation remains mostly untested. CC is a complex intervention and there is significant variation in the exact nature of the interventions used in different trials. A number of study-level factors which have already shown to influence the effects of CC for depressive symptoms are the inclusion of a recognised psychological treatment (e.g. behavioral activation, problem solving) either on its own or combined with medication management, recruitment of patients using systematic or population health approaches (e.g. disease registers), and regular clinical supervision of care managers. [14] Equally, patient factors may influence the effectiveness of CC for suicidal ideation. Both previous trials which have shown that CC has promising effects on suicide risk but were solely based on older adults with depression and currently there is lack of evidence about the effects of CC on suicidal ideation among younger patients. Moreover, CC has been increasingly seen as a promising framework for integrating care for people with depression and comorbid chronic physical conditions rather than an intervention targeting depression alone. $[15,16]$ The National Institute for Health and Care Excellence (NICE) guidance in the UK also recommends CC as treatment of choice in people with comorbid depressive disorders and chronic physical conditions. [9,17]

In this study, we conducted an individual participant data (IPD) meta-analysis to examine whether CC is effective for reducing suicidal ideation among adult patients with depression at short-term follow-up compared with usual care. We also examined different delivery models of CC (i.e. intervention content, recruitment method, supervision frequency of the care manager, risk of bias) and a number of subgroups of patients (by age, gender, and number/types of chronic physical conditions).

\section{Methods}

The IPD meta-analysis followed a registered (PROSPERO CRD201747) protocol and a statistical analysis plan. Findings are reported in line with the Preferred Reporting Items for Systematic reviews and Meta-Analysis of Individual Participant Data (PRISMA-IPD) (eTable 1 in the supplement). [18]

\subsection{Search methods}

Bibliographic databases were searched to update the Cochrane review in September 2019 (Medline, Embase, PubMed, PsycINFO, CINAHL, and Cochrane Central Register of Controlled Trials (CENTRAL)). The search strategy is further described elsewhere [14] and the search and collection of eligible studies was ongoing until 30th April 2020. The reference lists of all included trials, reviews [19] and trial registers (ClinicalTrials.gov, ISCTRN) were searched to identify any unpublished and/or important ongoing trials. Authors of all included studies and experts in the field were asked to identify additional published studies and trials in progress. 


\subsection{Eligibility criteria}

Studies were selected for inclusion in the IPD analysis if they were:

- RCTs or cluster RCTs testing collaborative care (multi-professional approach to patient care, structured management plan, scheduled patient follow-ups, and enhanced inter-professional communication) in comparison with usual care or enhanced usual care;

- based on adults (age above 17 years) with depression or mixed anxiety and depressive disorder; and

- reported depression scales that included one-item scores for suicidal ideation outcomes four to six months after randomisation.

Studies involving adolescents and children were excluded due to differences in the remit of mental health services and depression management interventions provided to children, adolescents and adults. [20]

\subsection{Measuring suicidal ideation and chronic physical conditions}

Suicidal ideation was assessed using continuous one-item scores extracted from the following continuous validated scales of depression: item nine of the Patient Health Questionnaire 9 (PHQ9) (10 studies), [21] item three of the Hamilton Depression Rating (HAMD) (3 studies), [22] item nine of the Beck Depression Inventory (BDI) (5 studies), [23] item 20 of the Depression Symptom Checklist 90 (SCL-90) (2 studies), [24] item 13 from the Depression Symptom Checklist 20 (SCL-20) (5 studies), item 10 from the Montgomery and Asberg Depression Rating Scale (MADRS) (2 studies), [25] and item nine from the Revised Clinical Interview Schedule for Depression (CIS-D) [26] (1 study). We focused on short-term suicide ideation items (extracted from depression scales) reported between 4 and 6 months after randomisation as most studies reported data availability for short-term follow-ups.

The presence and number of chronic physical conditions were assessed using validated comorbidity indices such as the Charlson Comorbidity Index, or empirical lists of chronic physical conditions. Eighteen comparisons (58\%) identified the types of physical conditions and these enabled us to classify participants as having 1 out of 5 conditions: type 2 diabetes (15 comparisons), cancer (8 comparisons), cardiovascular disease (15 comparisons), hypertension (10 comparisons), and respiratory disease (11 comparisons).

\subsection{Data analysis}

Study authors were contacted to obtain primary individual-patient data sets for the following variables: treatment group, age, gender, baseline and follow-up suicidal ideation assessment scores, and number and types of physical chronic conditions. Information on populations, interventions, risk of bias, and outcome effect sizes were extracted from published reports using a standardised data extraction form by two independent reviewers (CG, MP). IPD data were cleaned, quality checked and amalgamated into a single data set. Initial separate analyses on depression outcomes were conducted for each study to ensure that analyses were consistent with those reported in the original studies. The full list and codes of variables requested from all IPD collaborators are reported in eTable 2 in the supplement.

Multiple imputation techniques were used to obtain more complete individual study datasets and to protect against bias due to data missing at random (MAR), missing completely at random (MCAR) or missing not at random (MNAR). In all three cases, multiple imputation is a method of addressing this bias. [27] Missing values for suicidal ideation scores at follow-up and age were imputed with a single multivariate normal imputation algorithm across 1000 datasets (mi impute mvn in Stata, v15; StataCorp) using Markov Chain Monte Carlo. [28,29] Each complete dataset was then combined according to Rubin's rules and analysed. [30] The imputation model regressed age (incomplete predictor), suicidal ideation (incomplete outcome), treatment group, baseline suicidal ideation score, gender (complete predictors) and a study identification variable to account for clustering within studies. Including the outcome in the imputation model is essential, although imputing the outcome does not confer significant analytical benefits. [27] We estimated the imputed values conditional on the observed values of the variables of interest.

Two independent reviewers assessed the quality of the randomised controlled trials using the Cochrane risk of bias tool. Additional quality checks involved baseline imbalance and missing data. One-stage IPD meta-analysis is known to be less susceptible to bias, more efficient in terms of power [31] and allows for advanced modelling of covariates (treatment-covariate interactions). [32-34] Our outcome was suicidal ideation, assessed at baseline and at 4 or 6 month follow-up post-randomisation, and we applied one-stage meta-analysis with mixed-effects models including fixed study-specific intercepts, random treatment effect, fixed study specific effects for baseline suicide ideation, fixed effects for age, gender and moderators. The analysis allowed us to separate out the within-study and across-study interactions (accounting for clustering) and avoid ecological biases by centring of the key covariates (age, gender). Suicidal ideation scores were standardised within each study, using study-specific means of the follow-up scores and the standard deviation of the baseline score. Two sensitivity analyses were performed to evaluate the consistency of the findings across i) imputed and non-imputed approaches (complete case analysis) and ii) measures of suicidal ideation (only retaining the most common measure - the ninth item of the PHQ9- in the analyses).

We conducted pre-specified primary 'subgroup' analyses to examine whether study-level and patient-level factors moderated the effects of CC on suicidal ideation. Study-level moderators included (each as binary): intervention content (medication management only; psychological/both), supervision frequency of the care manager (regular such as weekly supervision versus no regular supervision, recruitment method of participants (systematic identification of versus referred by clinician) and risk of bias. Allocation concealment was selected as an indicator of risk of bias, as it is sensitive to changes in the treatment effect, especially for self-reported outcomes. [35-37] Patient-level moderators included: age (categorical variable: 17 to 25 years age group; 26 to 65 years age group; and older than 65 age group), gender (binary variable), number of chronic physical conditions (continuous variable), and types of chronic physical conditions (each as a binary: diabetes, cancer, cardiovascular disease, hypertension, and respiratory disease).

Control for cluster-allocated RCTs in the model was achieved by adherence to the methodological recommendations of Sutton. [38] Stata's (v16.1) mixed and ipdforest $[39,40]$ commands were used to pool evidence from studies and to obtain forest plots, respectively. Restricted maximum likelihood was used for model estimation. Heterogeneity was assessed with a one-stage meta-analysis variant of the $\mathrm{I}^{2}$ statistic and the estimated inter-study variance $(\tau 2)$. [41] If studies included multiple treatment groups and a single control group, the treatment groups were treated as separate comparisons in the analyses, whereas the control groups were halved at random to avoid double counting in the analyses. In accord with published guidelines, [42] if more than 10 studies were available, we would use contour-enhanced funnel plots to assess publication bias alongside visual examination and statistical tests for asymmetry (Egger's test for continuous outcomes).

\section{Results}

As shown in the PRISMA IPD flowchart (Fig. 1), IPD were collected from 28 trials (31 comparisons), which included 11,688 participants corresponding to $41 \%$ of participants from eligible trials. A total of 11,165 unique cases for the primary outcome were analysed, of which 2125 (19.03\%) were missing at follow-up and were imputed using multiple imputations.

Most participants in the IPD were women (8058 [68.9\%]) and the 


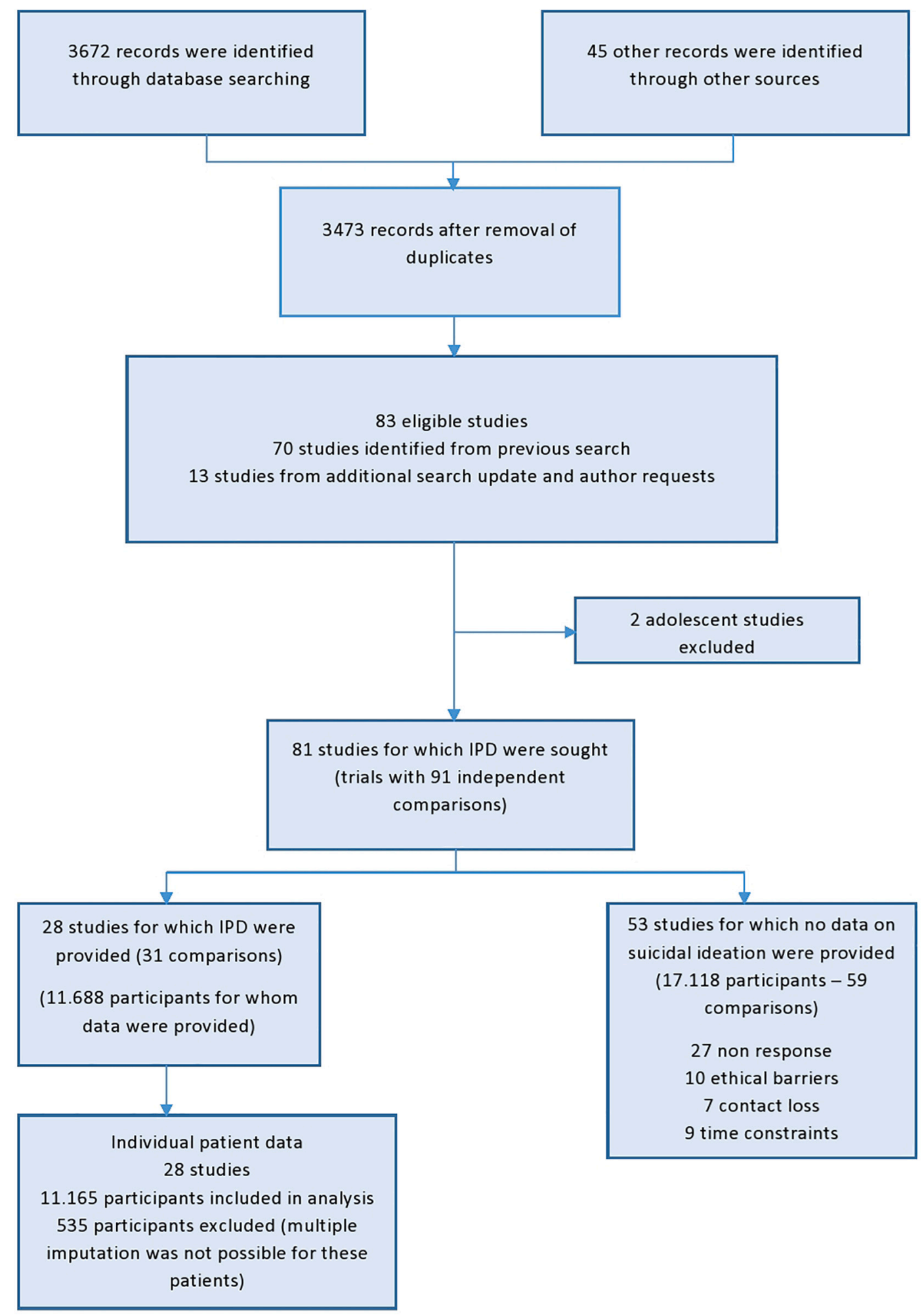

Fig. 1. PRISMA flowchart.

mean (SD) age was 54.5 ( $\mathrm{SD}=16.6$ ) years (range, 17-95 years). As many as 8204 [70.2\%] participants had at least one physical condition and up to 20 conditions with a median of 2.5 conditions (IQR: 1 to 4 conditions). Table 1 presents the baseline characteristics of patients included in the IPD by intervention arm. Thirteen studies (46.5\%) in the IPD were conducted in the United States, [43-55] thirteen (46.5\%) in Europe, [56-68] one (3.5\%) in Canada, [69] and one (3.5\%) in India. [70] We provide a summary table of IPD main effect and all moderator and sensitivity analyses in Table 2 . The full descriptive characteristics of the included studies are presented eTable 3 and eTable 4 in the supplement. Studies with IPD were compared with studies where IPD could not be retrieved to evaluate the outcome, population, intervention, and risk of bias characteristics and these comparisons are reported in eTable 5 in the supplement. The only statistically significant differences were for country of studies and intervention content. We were able to obtain data from a larger proportion of trials from countries other than 
Table 1

Baseline characteristics of participants by intervention arm.

\begin{tabular}{|c|c|c|}
\hline Participant characteristics & $\begin{array}{l}\text { Collaborative care } n= \\
6223(53.2)\end{array}$ & $\begin{array}{l}\text { Usual care } n= \\
5465(46.8)\end{array}$ \\
\hline \multicolumn{3}{|l|}{ Gender } \\
\hline Men, n (\%) & $1926(31)$ & $1703(31.2)$ \\
\hline Women, n (\%) & $4297(69)$ & $3761(68.8)$ \\
\hline \multicolumn{3}{|l|}{ Age } \\
\hline Mean age (SD) & $54.9(16.6)$ & $53.5(16.7)$ \\
\hline 17-25 years, $\mathrm{n}(\%)$ & $316(5.3)$ & $261(5)$ \\
\hline 26-65 years, n (\%) & $3912(65.6)$ & $3312(63.6)$ \\
\hline$\geq 65$ years, $\mathrm{n}(\%)$ & $1732(29.1)$ & $1632(31.4)$ \\
\hline Suicidal ideation, mean (SD) & $1.03(3.32)$ & $1.01(3.08)$ \\
\hline \multicolumn{3}{|l|}{ Chronic physical conditions } \\
\hline $\begin{array}{l}\text { Mean chronic physical } \\
\text { conditions (SD) }\end{array}$ & $2.49(2.33)$ & $2.57(2.22)$ \\
\hline $\begin{array}{l}\text { Any chronic physical } \\
\text { condition, } \mathrm{n}(\%)\end{array}$ & $4293(81.4)$ & $3911(82.4)$ \\
\hline Cardiovascular disease, $\mathrm{n}(\%)$ & $1418(38.7)$ & $1421(40.4)$ \\
\hline Type 2 Diabetes, n (\%) & $1111(29.2)$ & $1095(30)$ \\
\hline Cancer, n (\%) & $220(8)$ & $210(8.1)$ \\
\hline Hypertension, n (\%) & $1215(44.5)$ & $1224(46.4)$ \\
\hline Respiratory disease, n (\%) & 687 (20.7) & $657(20.6)$ \\
\hline
\end{tabular}

Suicidal ideation standardised score range, 0 to 4 , with high scores indicating greater suicidal ideation.

the USA and from a larger proportion of trials with a recognised psychological treatment model.

Collaborative care was associated with a small but significant effect on suicidal ideation compared with usual care (SMD, -0.13 , 95\% CI, -0.16 to -0.09 ) (Fig. 2) in the analysis with imputed values. Analysis without the imputed values was similar (SMD, -0.12 [95\% CI, -0.17 to $-0.07] ; \mathrm{I}^{2}=0.74 \% ; 0.13 \%-4.24 \%$ ) with participants from all 28 RCTs and for this reason we report results only for those models with the imputed values. The sensitivity analysis including only studies that used the ninth item of the PHQ9 to measure suicidal ideation results were nearly identical (SMD, -0.13 [95\% CI, -0.22 to -0.03 ] (eFigure 3 in the supplement).

The interaction term between intervention content and CC was statistically significant (interaction coefficient, -0.14 [95\%CI, -0.24 to $-0.04]$ ) whilst controlling for baseline suicide ideation score, age and gender, indicating that intervention content influences the treatment effect. More specifically, CC interventions which included a recognised psychological treatment model were associated with small significant reductions in suicidal ideation (SMD, -0.15 [95\%CI, -0.19 to -0.11$]$ ) whereas CC interventions which only included medication management plans did not show statistically significant reduction of suicidal ideation (SMD, -0.01 [ -0.10 to 0.08$]$ ) (eFigure 1 in the supplement).

For age, our reference group were people aged 26 to 65 years, as rates of suicide and attempted suicide are higher in adolescents and in the elderly, when compared to the middle age group. [71] The interaction term between age and CC was statistically significant for the elderly aged 66 to 95 (interaction coefficient, -0.10 [95\% CI -0.18 to $-0.01]$ ) but non-significant for younger adults aged 17 to 25 years (interaction coefficient, -0.03 [ $95 \% \mathrm{CI}-0.15$ to 0.09 ] controlling for the baseline scores of suicidal ideation, gender and number of chronic physical conditions. CC was mostly effective in reducing suicidal ideation in older people (SMD, -0.19 [95\% CI, -0.25 to -0.12$]$ ) followed by younger adults 17 to 25 years (SMD, -0.18 [95\% CI, -0.34 to -0.02 ]) (although the confidence intervals varied widely in this group indicating non-significance) and people aged between 26 and 65 (SMD, -0.09 [95\%CI, -0.14 to -0.05$]$ ) (eFigure 2 in the supplement).

The interaction between the number of chronic physical conditions and CC was not statistically significant (interaction coefficient, -0.01 [95\% CI, -0.03 to 0.01$]$ ) (eFigure 4 in the supplement) indicating that the effects of CC are equivalent for people with LTCs and without LTCs. The interaction terms between individual type of chronic physical
Table 2

Summary table of IPD main effect and all sensitivity analyses.

\begin{tabular}{|c|c|c|c|}
\hline & $\begin{array}{l}\text { Effect (SMD) } \\
\text { and } 95 \% \text { CI }\end{array}$ & $\begin{array}{l}\text { Included } \\
\text { studies }\end{array}$ & $\begin{array}{l}\text { Heterogeneity Levels } \\
\text { (I2 statistic) }\end{array}$ \\
\hline Main effect & $\begin{array}{l}-0.13,95 \% \text { CI } \\
-0.16 \text { to }-0.09\end{array}$ & 28 & $\begin{array}{l}0.74,95 \% \text { CI } 0.13 \text { to } \\
4.24\end{array}$ \\
\hline \multicolumn{4}{|c|}{ Effect of patient level moderators } \\
\hline $17-30$ years, $\mathrm{n}(\%)$ & $\begin{array}{l}-0.13,95 \% \text { CI } \\
-0.24 \text { to }-0.02\end{array}$ & 21 & $\begin{array}{l}0.65,95 \% \text { CI } 0.09 \text { to } \\
4.67\end{array}$ \\
\hline $31-65$ years, $n(\%)$ & $\begin{array}{l}-0.09,95 \% \mathrm{CI} \\
-0.14 \text { to }-0.05\end{array}$ & 27 & \\
\hline$\geq 65$ years, $n(\%)$ & $\begin{array}{l}-0.19,95 \% \text { CI } \\
-0.25 \text { to }-0.12\end{array}$ & 27 & \\
\hline \multicolumn{4}{|l|}{ Gender } \\
\hline Male & $\begin{array}{l}-0.15,95 \% \text { CI } \\
-0.23 \text { to }-0.08\end{array}$ & 28 & $\begin{array}{l}0.69,95 \% \text { CI } 0.11 \text { to } \\
4.34\end{array}$ \\
\hline Female & $\begin{array}{l}-0.10,95 \% \mathrm{CI} \\
-0.16 \text { to }-0.05\end{array}$ & 28 & \\
\hline $\begin{array}{l}\text { Presence of chronic } \\
\text { physical conditions at }\end{array}$ & $\begin{array}{l}-0.14,95 \% \text { CI } \\
-0.18 \text { to }-0.09\end{array}$ & 24 & $\begin{array}{l}0.64,95 \% \text { CI } 0.09 \text { to } \\
4.19\end{array}$ \\
\hline $\begin{array}{l}\text { Number of chronic } \\
\text { physical conditions }\end{array}$ & $\begin{array}{l}-0.01,95 \% \mathrm{CI} \\
-0.03 \text { to } 0.01\end{array}$ & 24 & $\begin{array}{l}0.91,95 \% \text { CI } 0.17 \text { to } \\
4.78\end{array}$ \\
\hline $\begin{array}{l}\text { Cardiovascular disease, } \\
\mathrm{n}(\%)\end{array}$ & $\begin{array}{l}-0.15,95 \% \text { CI } \\
-0.23 \text { to }-0.08\end{array}$ & 18 & - \\
\hline Type 2 diabetes, n (\%) & $\begin{array}{l}-0.16,95 \% \text { CI } \\
-0.24 \text { to }-0.07\end{array}$ & 19 & - \\
\hline Cancer, n (\%) & $\begin{array}{l}-0.21,95 \% \text { CI } \\
-0.40 \text { to }-0.02\end{array}$ & 11 & - \\
\hline Hypertension, n (\%) & $\begin{array}{l}-0.16,95 \% \text { CI } \\
-0.25 \text { to }-0.08\end{array}$ & 13 & - \\
\hline $\begin{array}{l}\text { Respiratory disease, } \mathrm{n} \\
(\%)\end{array}$ & $\begin{array}{l}-0.19,95 \% \text { CI } \\
-0.30 \text { to }-0.08\end{array}$ & 14 & - \\
\hline
\end{tabular}

Effect of study level moderators

Intervention content

Medication only

Psychological or mixed

$-0.01,95 \% \mathrm{CI}$

-0.10 to 0.08

$-0.15,95 \%$ CI

-0.19 to -0.11

$-0.10,95 \% \mathrm{CI}$

Allocation concealment

(High risk of bias)

Supervision frequency

-0.15 to -0.04

$-0.13,95 \% \mathrm{CI}$

-0.19 to -0.08

(Scheduled)

Recruitment method

Referral

$-0.07,95 \% \mathrm{CI}$

-0.23 to -0.09

Systematic identification $\quad-0.12,95 \% \mathrm{CI}$

-0.16 to -0.08

conditions and CC were all non-significant: cancer (interaction coefficient, -0.04 [ $95 \% \mathrm{CI},-0.24$ to 0.16$]$ ), cardiac disease (interaction coefficient, $-0.01 \quad[95 \% \mathrm{CI},-0.09$ to 0.09$]$ ), diabetes (interaction coefficient, -0.01 [95\% CI, -0.11 to 0.09$]$ ), hypertension (interaction coefficient, -0.02 [95\%CI, -0.13 to 0.09$]$ ), and respiratory disease (interaction coefficient, -0.05 [95\% CI, -0.17 to 0.08$]$ ) (eFigures $5-9$ in the supplement).

The interaction effect between gender and the treatment effect was non-significant (interaction coefficient, -0.06 [95\%CI -0.13 to 0.02$]$ ) (eFigure 10 in the supplement) controlling for the baseline scores of suicidal ideation and age. CC was associated with small significant reductions in suicidal ideation for men (SMD, -0.17 [ -0.23 to -0.10$]$ and women (SMD, -0.11 [ -0.15 to -0.06$]$ ). The pooled effect of CC was not moderated by supervision frequency (interaction coefficient, -0.01 [95\%CI, -0.08 to 0.06$]$ ); eFigure 11 in the supplement), recruitment method (interaction coefficient for systematic identification, -0.05 [95\%CI, -0.22 to 0.11 ]; interaction coefficient for referral, -0.10 [95\% CI, -0.28 to 0.01 ; ] eFigure 9 in the supplement) and risk of bias (interaction coefficient, 0.05 [ $95 \% \mathrm{CI},-0.02$ to 0.13 ]; eFigure 10 in the supplement).

No visual or statistical evidence (Egger's test $P=0.86$ ) of small study effects was found in the contour-enhanced funnel plot (eFigure 12 in the supplement). 


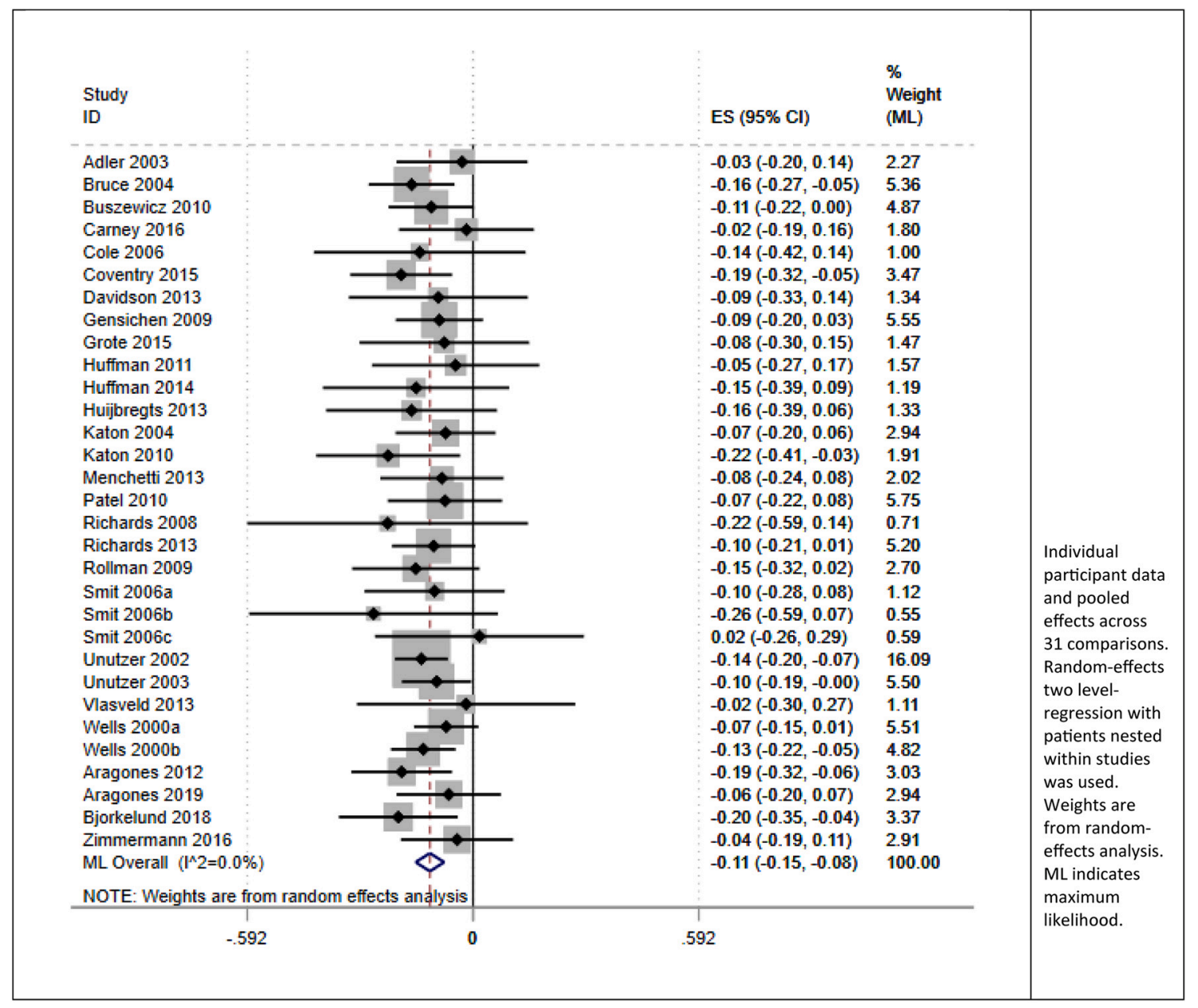

Fig. 2. Main effect of collaborative care interventions on suicidal ideation.

\section{Discussion}

This large IPD meta-analysis showed that collaborative care is associated with small, significant reductions in suicidal ideation for patients with depression at four to six months post-intervention. Embedding a recognised psychological treatment within CC either on its own or combined with medication management was found to be an important factor for achieving greater reductions on suicidal ideation. We also identified subgroups of participants for whom CC might be promising for therapeutically managing suicidal ideation. In particular, the patients' age successfully determined the effect of CC on suicidal ideation, rather than the effects of the number of chronic comorbidities. CC was mostly effective for reducing suicidal ideation in patients at age 65 and older whereas younger patient groups achieved very small reductions in suicidal ideation following CC. The effect of CC on suicidal ideation (SMD $=-0.18$ ) for those at age 65 or older was similar to the effect of CC on depression found in a previous IPD meta-analysis (SMD $=-0.22$ ) [72] and was equal to a drop of approximately 2 points on the PHQ-9 scale above the change in the controls. Our findings suggest CC is a promising framework for reducing suicidal ideation among older depressed primary care patients, especially when this framework is incorporated with psychological interventions.

The main strengths of this study include the large sample and the advanced IPD methodology which enabled us to analyse data from multiple studies and across several thousands of patients which have not been previously reported in published trials or aggregate data metaanalyses. The use of aggregate data meta-analysis would not be a viable option in this case because the published reports of CC trials do not report suicidal ideation outcomes. The IPD meta-analyses in conjunction with the use of multiple mixed-effects regression models, ANCOVA to adjust for baseline effect of the primary outcome, and the careful control for covariates allowed us to minimise biases that are usually found in aggregate data meta-analyses.

However, our study also has limitations. First, IPD meta-analysis is susceptible to important sources of bias, such as publication, study or reviewer selection, and data availability bias. To address these possible sources of bias, we plotted funnel plots and conducted formal tests, which showed that publication bias was not present in the final dataset. We minimised study selection bias by performing rigorous searches across multiple electronic bibliographic databases, contacting authors and using a strict pre-specification of trial eligibility criteria. This methodology allowed us to access data from approximately $39 \%$ of all available data included in the 83 published RCTs of collaborative care for depression. Although this is below the recommended recruitment target ( $80 \%$ of data requested), most IPD meta-analyses are only able to obtain $25 \%$ to $34 \%$ of the available data. [73] Another limitation of this study is that the main outcome (suicidal ideation) was measured using one item scores from different depression scales. Although we standardised the effects and sensitivity analysis showed no impact on the overall effect, future studies are needed to apply more comprehensive and validated measures of suicidal ideation to allow changes in suicide ideation to be better evaluated in clinical terms for informing policy. Finally, other potential factors, such as intensity of psychological intervention and care manager contacts which may moderate the effects of CC on suicidal ideation, are poorly reported in trials and we were therefore unable to evaluate their effects on our suicidal ideation. 
The literature on the efficacy of collaborative care in reducing suicidal ideation is limited. One large systematic review has concluded that suicide prevention strategies in primary care, such as screening programmes, are not particularly effective whereas evidence on the efficiency of physician training programmes or care management/CC is limited. [74] Conclusions or recommendations about the use of primary care suicide prevention programmes could not be supported by the available evidence [74] but the authors emphasised the importance of pharmacological and psychological treatment of depression as a suicide prevention strategy. Another systematic review, which examined suicide interventions in primary care, concluded that CC is effective at reducing suicide rates in primary care patients while there is very little evidence that alternative approaches such as practitioner education and screening for suicide risk are effective. [75]

Our IPD meta-analysis addressed this important research gap and the findings are in line with the direct evidence derived from the three pivotal clinical trials (PROSPECT, IMPACT and INDI) found that CC could be a useful strategy for reducing suicidal ideation, especially for the older adults. [11-13] Our results indicate that CC interventions that include psychological therapy improve suicidal ideation more than CC interventions without psychological treatment. Nevertheless, the effects of CC are equivalent for people with LTCs and without LTCs. These findings agree with previous evidence on the effectiveness of CC interventions for depressed patients and suggest that improvements in depression scores may be the main driver of reductions in suicidal ideation scores. Even though the effects of CC on suicidal ideation were smaller compared to the effects of CC on depression, evidence suggests that depressed patients with suicidal ideation may continue experiencing suicidal ideation even when the other depressed symptoms are in remission. [76-78]

The main message of this study is that CC can be a potentially viable and effective framework for managing suicidal ideation in primary care settings. To be effective, such programs should include an evidencebased psychological intervention and they are likely to be most effective for older adults who are at the highest risk for completed suicide. One key advantage of CC is a strong focus on the systematic measurement and management of physical and mental health conditions which can be a useful tool to improve suicidal ideation for older people. Considering that suicidal ideation can be persistent and strongly predictive of future episodes of self-harm or deaths by suicide, prospective suicide prevention strategies which integrate CC in primary care are highly encouraged by our findings. This study is the first attempt to synthesise findings of the effectiveness of CC on suicide ideation and shows that CC is effective in reducing suicide ideation at short-term follow-ups. Future studies may be able to discern long-term effects of CC on suicide ideation.

This IPD meta-analysis is the largest and most rigorous assessment to date that shows CC could effectively reduce suicidal ideation in adults with depression. Our findings support the large-scale implementation of CC programs and commissioning larger CC trials (with embedded psychological interventions) to reduce suicidal ideation among older adults. Additional research to refine such programs for younger adults at risk for suicide is also warrant.

\section{Author contributions}

MP and CFC had the initial research idea and obtained funding for this study. CFC and MP CG formulated the research questions and designed the study. CFC, MP and CG searched for published work, selected articles, and approached authors for data. CG extracted and analysed data, and CFC and MP drafted the protocol and manuscript. AH and SZ and helped in data selection and in the data extraction. CG, MP and CFC substantially contributed in designing the searches and the statistical analysis plan, writing of the manuscript, and interpreting the findings. $\mathrm{AH}, \mathrm{SZ}, \mathrm{EK}, \mathrm{PB}$, and $\mathrm{PC}$ substantially contributed to the manuscript by providing review comments and edits. All authors have read and approved the final manuscript.

\section{Funding}

This study was funded by the National Institute of Health Research (NIHR) School for Primary Care Research. The research team members were independent from the funding agencies. The views expressed in this manuscript are those of the authors and not necessarily those of the National Health Service, the NIHR, or the Department of Health. The funders had no role in the design and conduct of the study; the collection, management, analysis, and interpretation of the data; and the preparation, review, or approval of the manuscript.

\section{Declaration of interests}

All authors have completed the ICMJE uniform disclosure form at www.icmje.org/coi_disclosure.pdf and all other authors declare no support from any organisation for the submitted work; no financial relationships with any organisations that might have an interest in the submitted work in the previous three years; and no other relationships or activities that could appear to have influenced the submitted work.

\section{Disclaimer}

The views expressed are those of the author(s) and not necessarily those of the NIHR Greater Manchester Patient Safety Translational Research Centre or the Department of Health and Social Care.

\section{Ethical approval}

Not required

\section{Data sharing}

Data are available upon request from the corresponding author.

\section{Author statement}

We would like to thank both reviewers and the editor for the time they spent reviewing our work. Overall, their assessment of the paper was positive and very useful suggestions were provided which we feel have improved the paper considerably. All points raised are addressed one-by-one, and we also provide a supplementary file where all the resulting changes from the original submission are highlighted to facilitate the review process.

\section{Supplementary data}

Supplementary data to this article can be found online at https://doi. org/10.1016/j.genhosppsych.2021.04.004.

\section{References}

[1] WHO. World Health Organisation. WHO Suicide Data. 2017.

[2] Aaronson ST, Sears P, Ruvuna F, Bunker M, Conway CR, Dougherty DD, et al. A 5year observational study of patients with treatment-resistant depression treated with vagus nerve stimulation or treatment as usual: comparison of response, remission, and suicidality. Am J Psychiatry 2017;174(7):640-8.

[3] Jacobs DG, Baldessarini RJ, Conwell Y, Fawcett JA, Horton L, Meltzer H, et al. Assessment and treatment of patients with suicidal behaviors. 2010.

[4] Goldberg DP, Blackwell B. Psychiatric illness in general practice: a detailed study using a new method of case identification. BMJ. 1970;2(5707):439-43.

[5] Andersen UA, Andersen M, Rosholm J, Gram L. Contacts to the health care system prior to suicide: a comprehensive analysis using registers for general and psychiatric hospital admissions, contacts to general practitioners and practising specialists and drug prescriptions. Acta Psychiatr Scand 2000;102(2):126-34.

[6] Luoma JB, Martin CE, Pearson JL. Contact with mental health and primary care providers before suicide: a review of the evidence. Am J Psychiatry 2002;159(6): 909-16. 
[7] Pearson A, Saini P, Da Cruz D, Miles C, While D, Swinson N, et al. Primary care contact prior to suicide in individuals with mental illness. Br J Gen Pract 2009;59 (568):825-32.

[8] Gilbody S, Bower P, Fletcher J, Richards D, Sutton AJ. Collaborative care for depression: a cumulative meta-analysis and review of longer-term outcomes. Arch Intern Med 2006;166(21):2314-21.

[9] Katon W, Unutzer J. Collaborative care models for depression: time to move from evidence to practice. Arch Intern Med 2006;166(21):2304-6.

[10] Hofstra E, Van Nieuwenhuizen C, Bakker M, Özgül D, Elfeddali I, de Jong SJ, et al Effectiveness of suicide prevention interventions: a systematic review and metaanalysis. Gen Hosp Psychiatry 2020;63:127-40.

[11] Alexopoulos GS, Reynolds III M, Charles F, Bruce ML, Katz IR, Raue PJ, et al. Reducing suicidal ideation and depression in older primary care patients: 24 month outcomes of the PROSPECT study. Am J Psychiatry 2009;166(8):882-90.

[12] Unützer J, Tang L, Oishi S, Katon W, Williams Jr JW, Hunkeler E, et al. Reducing suicidal ideation in depressed older primary care patients. J Am Geriatr Soc 2006; 54(10):1550-6.

[13] Aragonès EC, Antonia \& Lopez-Cortacans, German \& Piñol, Josep. El programa INDI per al maneig de la depressió en atenció primària. Anàlisi de la seva eficàcia per disminuir la ideació suïcida. Ann Med 2016;99:51-4.

[14] Coventry PA, Hudson JL, Kontopantelis E, Archer J, Richards DA, Gilbody S, et al. Characteristics of effective collaborative care for treatment of depression: a systematic review and meta-regression of 74 randomised controlled trials. PLoS One 2014;9(9):e108114.

[15] de Heer EW, Ten Have M, van Marwijk HW, Dekker J, de Graaf R, Beekman AT, et al. Pain as a risk factor for suicidal ideation. A population-based longitudinal cohort study. Gen Hosp Psychiatry 2020;63:54-61.

[16] Castelijns H, Eijsbroek V, Cees AT, van Marwijk HW, van der Feltz-Cornelis CM. Illness burden and physical outcomes associated with collaborative care in patients with comorbid depressive disorder in chronic medical conditions: a systematic review and meta-analysis. Gen Hosp Psychiatry 2018;50:1-14.

[17] Ekers DMR, Archer J, Ebenezer C, Kemp D, Gilbody S. Nurse-delivered collaborative care for depression and long-term physical conditions: a systematic review and meta-analysis. Rev J Affect Disord 2013;149(1-3):14-22.

[18] Stewart LA, Clarke M, Rovers M, Riley RD, Simmonds M, Stewart G, et al. Preferred reporting items for a systematic review and meta-analysis of individual participant data: the PRISMA-IPD statement. JAMA. 2015;313(16):1657-65.

[19] Archer J, Bower P, Gilbody S, Lovell K, Richards D, Gask L, et al. Collaborative care for depression and anxiety problems. Cochrane Database Syst Rev 2012;10.

[20] Department of Health. The National Service Framework for Mental Health. Modern Standards and Service Models. 1999.

[21] Kroenke K, Spitzer RL, Williams JB. The PHQ-9: validity of a brief depression severity measure. J Gen Intern Med 2001;16(9):606-13.

[22] Hamilton M. Rating depressive patients. J Clin Psychiatry 1980;41(12 Pt 2):21-4.

[23] Beck AT, Steer RA. Internal consistencies of the original and revised Beck depression inventory. J Clin Psychol 1984;40(6):1365-7.

[24] Derogatis LR, Fitzpatrick M. The SCL-90-R, the brief symptom inventory (BSI), and the BSI-18. 2004.

[25] Montgomery S, Åsberg M. A new depression scale designed to be sensitive to change: Acad. Department of Psychiatry, Guy's Hospital; 1977.

[26] Lewis G, Pelosi AJ, Araya R, Dunn G. Measuring psychiatric disorder in the community: a standardized assessment for use by lay interviewers. Psychol Med 1992;22(2):465-86.

[27] Kontopantelis E, White IR, Sperrin M, Buchan I. Outcome-sensitive multiple imputation: a simulation study. BMC Med Res Methodol 2017;17(1):2.

[28] Donders ART, Van Der Heijden GJ, Stijnen T, Moons KG. A gentle introduction to imputation of missing values. J Clin Epidemiol 2006;59(10):1087-91.

[29] Gadbury G, Coffey C, Allison D. Modern statistical methods for handling missing repeated measurements in obesity trial data: beyond LOCF. Obes Rev 2003;4(3): 175-84.30.

[30] Rubin DB. Multiple imputation for nonresponse in surveys. John Wiley \& Sons; 2004.

[31] Kontopantelis E. A comparison of one-stage vs two-stage individual patient data meta-analysis methods: a simulation study. Res Synth Methods 2018;9(3):417-30

[32] Simmonds M, Higgins J. Covariate heterogeneity in meta-analysis: criteria for deciding between meta-regression and individual patient data. Stats Med 2007;26 (15):2982-99.

[33] Stewart LA, Parmar MK. Meta-analysis of the literature or of individual patient data: is there a difference? Lancet. 1993;341(8842):418-22.

[34] Vickers AJ, Cronin AM, Maschino AC, Lewith G, MacPherson H, Foster NE, et al. Acupuncture for chronic pain: individual patient data meta-analysis. Arch Intern Med 2012;172(19):1444-5335.

[35] Higgins JP, Altman DG, Gøtzsche PC, Jüni P, Moher D, Oxman AD, et al. The Cochrane Collaboration's tool for assessing risk of bias in randomised trials. BMJ. 2011;343:d5928.

[36] Pildal J, Hrobjartsson A, Jørgensen K, Hilden J, Altman D, Gøtzsche P. Impact of allocation concealment on conclusions drawn from meta-analyses of randomized trials. Int J Epidemiol 2007;36(4):847-57.

[37] Schulz KF, Chalmers I, Hayes RJ, Altman DG. Empirical evidence of bias: dimensions of methodological quality associated with estimates of treatment effects in controlled trials. JAMA. 1995;273(5):408-12.

[38] Sutton AJ, Kendrick D, Coupland CA. Meta-analysis of individual-and aggregatelevel data. Stats Med 2008;27(5):651-69.

[39] Kontopantelis E, Reeves D. A short guide and a forest plot command (ipdforest) for one-stage meta-analysis. Stata J 2013;13(3):574-87.
[40] StataCorp. Stata Statistical Software: Release 12. College Station, TX: StataCorp LP; 2011.

[41] Higgins JP, Thompson SG. Quantifying heterogeneity in a meta-analysis. Stat Med 2002;21(11):1539-58.

[42] Ahmed I, Sutton AJ, Riley RD. Assessment of publication bias, selection bias, and unavailable data in meta-analyses using individual participant data: a database survey. BMJ. 2012;344:d7762.

[43] Adler DA, Bungay KM, Wilson IB, Pei Y, Supran S, Peckham E, et al. The impact of a pharmacist intervention on 6-month outcomes in depressed primary care patients. Gen Hosp Psychiatry 2004;26(3):199-209.

[44] Bruce ML, Ten Have TR, Reynolds III CF, Katz II, Schulberg HC, Mulsant BH, et al. Reducing suicidal ideation and depressive symptoms in depressed older primary care patients: a randomized controlled trial. JAMA. 2004;291(9):1081-91.

[45] Carney RM, Freedland KE, Steinmeyer BC, Rubin EH, Ewald G. Collaborative care for depression symptoms in an outpatient cardiology setting: a randomized clinical trial. Int J Cardiol 2016;219:164-71.

[46] Davidson KW, Bigger JT, Burg MM, Carney RM, Chaplin WF, Czajkowski S, et al. Centralized, stepped, patient preference-based treatment for patients with post-acute coronary syndrome depression: CODIACS vanguard randomized controlled trial. JAMA Intern Med 2013;173(11):997-1004.

[47] Grote NK, Katon WJ, Russo JE, Lohr MJ, Curran M, Galvin E, et al. Collaborative care for perinatal depression in socioeconomically disadvantaged women: a randomized trial. Depress Anxiety 2015;32(11):821-34.

[48] Huffman JC, Mastromauro CA, Beach SR, Celano CM, DuBois CM, Healy BC, et al. Collaborative care for depression and anxiety disorders in patients with recent cardiac events: the Management of Sadness and Anxiety in Cardiology (MOSAIC) randomized clinical trial. JAMA Intern Med 2014;174(6):927-35.

[49] Huffman JC, Mastromauro CA, Sowden GL, Wittmann C, Rodman R, Januzzi JLJP. A collaborative care depression management program for cardiac inpatients: depression characteristics and in-hospital outcomes. Psychosomatics. 2011;52(1): 26-33.

[50] Katon WJ, Lin EH, Von Korff M, Ciechanowski P, Ludman EJ, Young B, et al. Collaborative care for patients with depression and chronic illnesses. New Engl J Med 2010;363(27):2611-20.

[51] Katon WJ, Von Korff M, Lin EH, Simon G, Ludman E, Russo J, et al. The pathways study: a randomized trial of collaborative care in patients with diabetesand depression. Arch Gen Psychiatry 2004;61(10):1042-9.

[52] Rollman BL, Belnap BH, LeMenager MS, Mazumdar S, Houck PR, Counihan PJ, et al. Telephone-delivered collaborative care for treating post-CABG depression: a randomized controlled trial. JAMA. 2009;302(19):2095-103.

[53] Unützer J, Katon W, Callahan CM, Williams Jr JW, Hunkeler E, Harpole L, et al. Collaborative care management of late-life depression in the primary care setting: a randomized controlled trial. JAMA. 2002;288(22):2836-45.

[54] Wells KB, Sherbourne C, Schoenbaum M, Duan N, Meredith L, Unützer J, et al Impact of disseminating quality improvement programs for depression in managed primary care: a randomized controlled trial. JAMA. 2000;283(2):212-20.

[55] Unützer J, Katon WJ, Russo J, Simon G, Von Korff M, Lin E, et al. Willingness to pay for depression treatment in primary care. Psychiatr Serv 2003;54(3):340-5.

[56] Aragonès E, Piñol JL, Caballero A, López-Cortacans G, Casaus P, Hernandez JM, et al. Effectiveness of a multi-component programme for managing depression in primary care: a cluster randomized trial. The INDI project. J Affect Disord 2012, 142(1-3):297-305.

[57] Aragonès E, Rambla C, López-Cortacans G, Tomé-Pires C, Sánchez-Rodríguez E, Caballero A, et al. Effectiveness of a collaborative care intervention for managing major depression and chronic musculoskeletal pain in primary care: a clusterrandomised controlled trial. J Affect Disord 2019;252:221-9.

[58] Björkelund C, Svenningsson I, Hange D, Udo C, Petersson E-L, Ariai N, et al. Clinical effectiveness of care managers in collaborative care for patients with depression in Swedish primary health care: a pragmatic cluster randomized controlled trial. BMC Fam Pract 2018;19(1):28.

[59] Buszewicz M, Griffin M, McMahon EM, Beecham J, MJBp King. Evaluation of a system of structured, pro-active care for chronic depression in primary care: a randomised controlled trial. BMC Psychiatry 2010;10(1):61.

[60] Coventry P, Lovell K, Dickens C, Bower P, Chew-Graham C, McElvenny D, et al. Integrated primary care for patients with mental and physical multimorbidity: cluster randomised controlled trial of collaborative care for patients with depression comorbid with diabetes or cardiovascular disease. BMJ. 2015;350: h638.

[61] Gensichen J, von Korff M, Peitz M, Muth C, Beyer M, Güthlin C, et al. Case management for depression by health care assistants in small primary care practices: a cluster randomized trial. Ann Intern Med 2009;151(6):369-78.

[62] Huijbregts KM, de Jong FJ, van Marwijk HW, Beekman AT, Adèr HJ, Hakkaart-van Roijen L, et al. A target-driven collaborative care model for major depressive disorder is effective in primary care in the Netherlands. A randomized clinical trial from the depression initiative. J Affect Disord 2013;146(3):328-37.

[63] Richards D, Lovell K, Gilbody S, Gask L, Torgerson D, Barkham M, et al. Collaborative care for depression in UK primary care: a randomized controlled trial. Psychol Med 2008;38(2):279-87.

[64] Richards DA, Hill JJ, Gask L, Lovell K, Chew-Graham C, Bower P, et al. Clinical effectiveness of collaborative care for depression in UK primary care (CADET): cluster randomised controlled trial. BMJ. 2013;347:f4913.

[65] Smit A, Kluiter H, Conradi H, Van der Meer K, Tiemens B, Jenner J, et al. Shortterm effects of enhanced treatment for depression in primary care: results from a randomized controlled trial. Psychol Med 2006;36(1):15-26. 
[66] Vlasveld M, Van der Feltz-Cornelis C, Adèr H, Anema J, Hoedeman R, Van Mechelen W, et al. Collaborative care for major depressive disorder in an occupational healthcare setting. Br J Psychiatry 2012;200(6):510-1.

[67] Zimmermann T, Puschmann E, van den Bussche H, Wiese B, Ernst A, Porzelt S, et al. Collaborative nurse-led self-management support for primary care patients with anxiety, depressive or somatic symptoms: cluster-randomised controlled trial (findings of the SMADS study). Int J Nurs Stud 2016;63:101-11.

[68] Menchetti M, Sighinolfi C, Di Michele V, Peloso P, Nespeca C, Bandieri PV, et al. Effectiveness of collaborative care for depression in Italy. A randomized controlled trial. Gen Hosp Psychiatry 2013;35(6):579-86.

[69] Cole MG, McCusker J, Elie M, Dendukuri N, Latimer E, Belzile E. Systematic detection and multidisciplinary care of depression in older medical inpatients: a randomized trial. CMAJ. 2006;174(1):38-44.

[70] Patel V, Weiss HA, Chowdhary N, Naik S, Pednekar S, Chatterjee S, et al. Effectiveness of an intervention led by lay health counsellors for depressive and anxiety disorders in primary care in Goa, India (MANAS): a cluster randomised controlled trial. Lancet. 2010;376(9758):2086-95.

[71] Nordentoft M. Prevention of suicide and attempted suicide in Denmark. Dan Med Bull 2007;54(4):306-69.

[72] Panagioti M, Bower P, Kontopantelis E, Lovell K, Gilbody S, Waheed W, et al. Association between chronic physical conditions and the effectiveness of collaborative care for depression: an individual participant data meta-analysis. JAMA Psychiat 2016;73(9):978-89.

[73] Thomas D, Radji S, Benedetti A. Systematic review of methods for individual patient data meta-analysis with binary outcomes. BMC Med Res Methodol 2014;14 (1):79.

[74] Zalsman G, Hawton K, Wasserman D, van Heeringen K, Arensman E, Sarchiapone M, et al. Suicide prevention strategies revisited: 10-year systematic review. Lancet Psychiatry 2016;3(7):646-59.

[75] Dueweke AR, Bridges AJ. Suicide interventions in primary care: a selective review of the evidence. Fam Syst Health 2018;36(3):289-302.

[76] Szanto K, Mulsant BH, Houck PR, Dew MA, Dombrovski A, Pollock BG, et al. Emergence, persistence, and resolution of suicidal ideation during treatment of depression in old age. J Affect Disord 2007;98(1-2):153-61.

[77] Tondo L, Lepri B, Baldessarini RJ. Suicidal status during antidepressant treatment in 789 Sardinian patients with major affective disorder. Acta Psychiatr Scand 2008; 118(2):106-15.

[78] Zisook S, Trivedi MH, Warden D, Lebowitz B, Thase ME, Stewart JW, et al. Clinical correlates of the worsening or emergence of suicidal ideation during SSRI treatment of depression: an examination of citalopram in the STAR* D study. J Affect Disord 2009;117(1-2):63-73. 